Portland State University

PDXScholar

$5-22-2020$

\title{
Emergence in the Strengths and Love of My People to Counter Invisibility for Liberation in the White Academy
}

Emily D. Carrillo-Casares

Portland State University

Follow this and additional works at: https://pdxscholar.library.pdx.edu/honorstheses

Part of the Public Health Commons

Let us know how access to this document benefits you.

\section{Recommended Citation}

Carrillo-Casares, Emily D., "Emergence in the Strengths and Love of My People to Counter Invisibility for Liberation in the White Academy" (2020). University Honors Theses. Paper 872.

https://doi.org/10.15760/honors.893

This Thesis is brought to you for free and open access. It has been accepted for inclusion in University Honors Theses by an authorized administrator of PDXScholar. Please contact us if we can make this document more accessible: pdxscholar@pdx.edu. 


\author{
Honors Thesis \\ Emily D. Carrillo-Casares \\ Portland State University
}

Kelly Gonzales, Ph.D., MPH, Associate Professor, School of Public Health

Email: kelly.gonzales@pdx.edu

Title: Emergence in the Strengths and Love of My People to Counter Invisibility for Liberation in the White Academy 


\begin{abstract}
Through a literature review and personal reflection, my thesis will focus on the strengths and love of my people to counter invisibility for liberation in the white academy. More importantly, my aim in this paper is to illustrate the strengths, courage, and will-power I came across to dismantle the concealed barriers in a system that misperceived my values. I will speak from the first person to express my feelings and experiences. When I use the words, my people, I mean people who identify themselves as Hispanic/Latino or non-white. The goal of this paper is to explicate how I remained strong and utterly myself in a system and spaces that uphold institutional racism and discern me as a stereotype. Then, I will take into consideration how this type of learning environment has on the emergence and professional development of other students who aspire to become future public health officials.
\end{abstract}

Keywords: Latino/Hispanic, public health, stereotype threat 


\section{Background/Historical Context}

The Hispanic and Latino population are considered to be one of the largest minority groups (Velasco-Mondragon et al.,2016). According to the United States Census 2019 Bureau website, Hispanic or Latino accounted for $18.3 \%$ of the population. In the year 2000 census, Latinos accounted for $12.5 \%$ of the population (Amero \& de la Torre, 2002). There was an increase of 5.8 percent of Latinos in America. According to Velasco et al., " Hispanics are disproportionately affected by poor conditions of daily life, shaped by structural and social position factors (such as macroeconomics, cultural values, income, education, occupation, and social support systems, including health services), known as social determinants of health (SDH)" (2016). This scholarly article utilizes a social-ecological framework to delineate literature reviews and national statistics on Hispanic health in the USA, the social determinants of health, health disparities, and many more (Velasco-Mondragon et al., 2016).

Research on the Latino community has not shed light on the health disparities that exist within the community. Latinos face an array of health issues, yet there has been no research that proves the reality. Amero and de la Torre (2002), argue, “... there are critical public health issues facing Latinas that must be better understood if interventions to eliminate racial and ethnic disparities in health care to be developed and implemented". How can the public health issues be diminished, without critical research focusing on race, sex, and class concerning health, is conducted? The public health literature calls attention to the debate on whether health care professionals should be culturally trained to comprehend and work with different communities. 
Integrating culturally trained professionals who utilize spontaneous self-affirmation (SSA), a values affirmation tool, can be the solution to eradicate health disparities.

\section{Public Health Debate}

A debate in the field of public health has been persistent. A debate that questions the patient and provider relationship. What is the role of the institutions; how can they help and train future health care professionals? Mitchell and Lassiter outline a set of suggestions to recruit underrepresented minorities. Camacho, Zangaro, and White (2017) argue that "diversifying the workforce remains a national priority". Then go on, "Diversifying the workforce has been shown to have benefits at the micro, meso, and macro levels" (Camacho, Zangaro \& White, 2017). From a micro level, we are talking patient-physician contact/interaction. At a macro level, the authors state, "at the macro or community level, diversifying the workforce can, in some cases, be effective in improving access to health care for certain minority populations" (2017). Enhancing the racial and ethnic diversity of health care workers is vital, yet the nation's responsibility.

Moving on, disparities are apparent in inpatient experiences, and the book by authors Lisa Cooper and Neil Powe highlights the continuation of racial and ethnic disparities within health care and writes about the relationship among patient-physician race and ethnic concordance to quality and satisfaction of care. Simply to state that a patient is satisfied when their physician understands them utterly disregarding ethnic and racial stereotypes. Cooper and Powe (2004) argue, “ health systems should optimize their providers' ability to establish rapport 
with minority patients to improve clinical practice and health care delivery" (Cooper and Powe, 2004). The text aims to improve the patient-provider relationship across racial and ethnic lines via the health care system. In the study of the impact of racial concordance on patient's ratings of care, conducted by Cooper and Powe, the findings implied that Hispanic patients with Hispanic physicians were satisfied with their quality of care. In brief, Cooper and Power (2004), state, “... there is support for the notion that increasing racial and ethnic diversity among physicians will provide ethnic minority patients with more choices and better experiences with care processes, including positive affect, longer visit duration, higher patient satisfaction, and better participation in care"(p.10). Several studies have focused on this debate, but there have been more studies focusing on the values affirmation tool and stereotype threat in a health care setting or an institution. However, it is salient to know that stereotype, discrimination, or prejudice, is a health disparity. Reducing disparities should be a priority; however, it is not an easy task.

\section{The field of Public Health}

The field of public health is very broad, as it focuses on promoting community health and eradicating health disparities and taking into consideration the social determinants of health. According to Healthy People 2020, the social determinants of health are conditions in which people reside and develop. The place is a huge role and predictor of one's health; therefore, a place that lacks an abundance of resources, accessibility to good quality of care, higher education, and economic mobility, can possibly have negative health outcomes. 
Additionally, the field of Public Health has been working in diversifying their field with healthcare professionals who are culturally trained. The article published in the American Journal of Public Health, the authors argued, "Several publications have shown the importance of a racially diverse workforce for improving underserved populations' access to care" ( Mitchell \& Lassiter, 2006). Eradicating health care disparities and magnifying the workforce with competent professionals, is a solution to health care dilemmas. The workforce is facing issues, when providing quality patient care, one of those issues is inadequate culturally competent training. In an article on the Consult $Q$ website, the author outlines five factors to improve and help assist the Latinos access to mental health care. Which are, removing the language barrier, collaborating with primary care physicians( PCPs), encouraging family involvement, offering sensitive, culturally competent treatment, and educating about the physiologic roots of mental illness (Campbell, 2017).

\section{A Latina's history}

In this section, I will write about my history, the dilemmas my past generations faced, and how those have affected the recent generations. Amaro and de la Torre (2002) states, "Research is needed that investigates the nature of discrimination experienced by Latinas through the process of cultural adaptation and the resulting effects on health and experiences in the health care delivery system" (p. 527). I am a daughter of two immigrant parents, both my mother and father were born and raised in Mexico. I'm part of a minority group in society, a group that is subordinate, marginalized, and disadvantaged. Growing up was a challenge due to my race, ethnicity, language, accent, and skin color. Since Spanish was my first language, learning English was challenging. During my first year of education (primary school/head-start), 
I recall being placed in an English Language Development program. Adjusting and experiencing acculturation was strenuous. I was taught to leave my tradition behind and act like the rest. Learning a new language, following the social norms, assimilating to the dominant culture, was stressful. Joint Center for Political and Economic Studies informs, “Acculturation stress and anti-immigrant discrimination are a reality for many immigrants and can have a harmful effect on mental, and in some cases physical, health" (p.8). Policy link's research in the field of public health examines how socio-economic and political factors play a role in community health and the existing disparities. "Stress is a factor of concern alongside health behavior. Researchers are increasingly interested in understanding how stress associated with acculturation and immigration affects the health of immigrants and subsequent generations" (Joint Center for Political and Economic Studies / PolicyLink, 2004, p.3. ). The fact of adjusting and relocating to a new country, filled with new people, languages, and norms, can be devastating and stressful. Fear of not fitting in, fear of being deported, losing their sense of self is dismay. Past generations with historical trauma can easily be transmitted to future generations in an obscure way with a detrimental effect. The devastating challenges, struggles, and cultural wounds my previous family generations encountered, accompanied by psychological stress, have utterly transmitted to my generation and lifestyle.

\section{Mental Health}

Mental health, depression, anxiety, or historical trauma are rarely discussed with family members. Research by Interian et al., (2010) confirms being labeled with depression is founded to be a stereotype. An individual with depression is viewed as someone with no will-power and a weak person. Interian and the including authors state, "Depression stigma among Latinos may be 
an underlying factor in deterring help-seeking" (Interian et al., 2010, p.2). Stigma itself affects individuals resulting in a wounded, sad, and low- self-esteem state.

Consequently, for the stigmatization it contains, and due to this, patients who deal with any mental illness are afraid to seek help and support. Most of the time, people dismiss this issue, which exacerbates their health. Dr. Diana Lorenzo stated, “ Many Latinos would prefer to ignore these conditions over talking about them openly" ("Overcoming Mental Health Stigma in the Latino Community, 2017’). Using this quote, I would like to briefly share my experience with mental illness and its profound impact on my personal and professional life. I would like to state how my mental health has been prolonged, of fear of being labeled abnormal, sick, or incompetent. I set high standards and expectations for myself-- ever since I entered high school. I grew up being asked the questions: "what are you going to be when you grow up?"; "what career fascinates you?" how can you set an example for your younger siblings"? These inquiries indeed made me ponder, mesmerize, contemplate my future life goals. The voices of these ongoing questions would be on my mind, overthinking. In my experience, I had no family involvement; my relationship with my family was not an ideal family connection. Which made it difficult to approach them and share about my struggles with anxiety.

At this moment, writing about my personal experience for my thesis, I feel anxious, with the simple reflection of my traumatic past coping with mental illness. To this day, I came across the realization of the importance of mental health and the impacts of one's wellbeing. For this specific reason, I was inspired to write about my experience, and more importantly, how I discovered my true inner self. Failure to me was not an option, neither the simple mere of saying no. I accepted any hard challenges to avoid the voice in my head. This was a personal issue I was 
dealing with alone, and I had no answers at the moment. The only way was to deal with it and move further on. To me, this was translating into a routine, and I assumed it was normal to have anxious thoughts about the future, or the muscle tension daily. An issue that was externally, but impacted my internal self was amid institutions, systems, and spaces that uphold institutional racism. These spaces discern me as limited, disempowered, and only viewed me as a stereotype.

\section{Literature Review}

I will conduct a literature review from compiled scholarly articles and-- more specifically analyze and meticulously review Kelly Gonzales’ project. Dr. Kelly Gonzales, a Ph.D. Professor at Portland State University studies health disparities on the American Indian (AI) and Alaska Native (AN) population. She closely studies the bias and discrimination within healthcare settings. Utilizing a values affirmation tool promotes an engaging patient and physician communication, simultaneously reducing the negative feelings and fear of being judged or stereotyped. This tool serves as a shield to protect the individual from feeling less competent or oppressed. I will analyze the effectiveness of this intervention, and analyze a previous study that investigated a values-affirmation intervention among American Indian women, to support the arguments in this paper. I aim to learn and find new approaches to mitigate health and racial disparities. A scholar and Author Amaro and de la Torre suggested, " Research on Latinas also is important because there are clear health conditions that disproportionately affect this population, and studies are needed to inform public health efforts to eliminate such health disparities" (Amaro and de la Torre, 2002, p.526). 
Indigenous women and men have a history of oppression, that, unfortunately, has passed onto the newer generations. Their experiences are similar to Hispanic's history, specifically the immigrants. This research highlights the health care disparities of women, and how they experience health care stereotype threat (HCST) in the health care setting, impacting their well-being. The main objective of this paper is to describe the minimal or no-minimal prenatal-care American Indian received, which harms their health and the baby's health. The values affirmation tool, a patient-centered technique, is emphasized in the paper. This tool is ideal for a patient and physician conversation at a health care appointment. The AI community struggle from mistrust, moderate engagement, and medical maltreatment. There is a limited number of culturally responsive health care, which can be exasperating for patients who have language as a barrier. Creating a safe health care environment requires culturally trained physicians who can connect with their patients, to satisfy their needs, and dismiss the continuous fears.

Previous studies show the poorer quality of care concerning ethnic minorities, but a few studies write about women's health regarding HCST and prenatal care. Moving on to the study conducted by Dr. Kelly and her colleagues, this study included two focus groups, a total of 40 pregnant women ages 18-45, who were given a survey before an appointment in the first phase. A survey that covered the presence of HCST and their values. In the second phase, the second group was placed in the values affirmation, followed with a before and after survey. Values affirmation tool may assist the physicians to acknowledge the patients' beliefs and values. In conclusion, the purpose was to find if a culturally tailored intervention can enhance 
patient-physician engagement. Nevertheless, more research, in the area of minority health, is substantially needed.

\section{Values Affirmation Tool}

How does a minority feel after utilizing a value affirmation tool before speaking with their primary physician or before entering an institution, or speaking with a healthcare professional? Patients who raise their self-esteem and know their value, are propelled to interact and feel belonged. I argue that it all initiates from one's self, we must self-affirm, to protect us from Healthcare stereotype threat (HCST). Notably, there is a need for patient-level interventions. The authors explain how the stereotype threat can be mitigated through a values affirmation tool. The article titled, "The Effect of Values Affirmation on Race-Discordant Patient-Provider Communication", illuminates the impacts of poor communication among African American patients and their health care providers who are white. The article states that these patients are afraid of being stereotyped, therefore, assert that using a values affirmation intervention, will ease the agitation. In conclusion, this intervention enhances patient-provider communication. The authors state that stereotype threat occurs when "members of certain groups fear being judged negatively according to stereotype" (Havranek, Hanratty, Tate C, et al, 2012). The values affirmation tool has shown great results in clinical settings. "Patients who performed the task asked more questions and provided more information about underlying medical conditions and expressed greater positive (interested, friendly, responsive, interactive, and respectful) and less negative (depressed and distressed) emotional tone" (Havranek, Hanratty, Tate C, et al, 2012). The article titled, "Spontaneous self-affirmation is associated with 
psychological well-being: Evidence from a US national adult survey sample" in the Journal of health psychology, provides data results from a study that focused on two specific questions. The hypothesis of this study was if self-affirmation was linked to demographics. The authors argued that self-affirmation is in a relationship with positive well-being. The spontaneous self-affirmation is highly emphasized to prove that it enhances an individuals' psychological self, personal health efficacy, happiness, and many other more. Another source that was published in Psychology \& health, concentrates on the linkage of spontaneous self-affirmation in a healthcare engagement, outcome, and seeking. The authors argue that spontaneous self-affirmation was associated with positive perceptions prior to speaking with health care providers; a higher chance of conducting inquiries in appointments; and a superior quality of care. In this paper the authors utilized cross-sectional data from a representative survey of U.S. adults to test differences of self-affirm associations in five distinct categories. Furthermore, they tested if patients faced stereotype threat in interactions with professionals in healthcare.

\section{Demographics- Latino-Stereotyped}

Not only African Americans experience this threat and fear in healthcare settings. Latinos/Hispanics have felt the same as any other minority group. Looking at the demographics, Latinos are the most with health care disparities. Parra-Cardona et al. (2016) concluded from their study, “...parents reported high levels of stress associated with being immigrants such as intense economic difficulties, experiences of racial discrimination in a variety of contexts, work exploitation,..." (p.6). Parenting interventions have been found as effective to reduce the numbers of mental health in the Hispanic community. In the study of Taber et al (2016), the authors noted 
how patients experience stereotype threat, and on top of that, in relation to Parra-Cardona's scholarly article, parents undergo heavy stress from their status in America. Perhaps incorporating a values affirmation tool will help ease the fear of being discriminated, stereotyped, and judged. Due to this, people avoid follow-up appointments, and instead of over-utilizing health care, they are underutilizing it. As a result, it creates a health dilemma, resulting in no reduction in health disparities.

The question that arises is, why do most Hispanics experience stereotype threat? This can be prevented through intervention. According to the article, Culturally Adapting an Evidence-Based Parenting Intervention for Latino Immigrants: The Need to Integrate Fidelity and Cultural Relevance" in the Family Process Journal, discusses the aims and effectiveness of a cultural adaptation program, and the research focusing on Latino Immigrant Parents. The findings display the cultural acceptability associated with an evidence-based intervention informed by Parent management (PMT) principles. The authors argue that cultural adaptation studies competent services to ethnic minorities. Following on, the authors argue that the sharing/spread of EBTs among minorities should have the adaptability to augment the cultural relevance in interventions.

A few disparities the Latino community face are similar to African Americans. Benjamins and Middleton (2019), asserts, “...perceived discrimination in the medical setting represents an emerging issue to be addressed for the growing Hispanic population and those who serve them" (p.12). Discrimination is vividly experienced in a health care setting, which is an issue when seeking health. Mistrust, fear of being stereotyped, language barrier, or an interaction with a physician that is not culturally competent are challenges that hinder a person of color to 
feel a sense of belonging. As Interian et al. stated in their research, the fear of being stereotyped inhibits one from reaching assistance. Additionally, Dr. Gonzales et al. study highlights the importance of value affirmation in a healthcare setting. Gonzales and the including authors argue, "Focusing on empowerment and culturally relevant strategies, such as those offered by the values-affirmation interventions, may help to heal and dismantle institutional racism and may be particularly effective within healthcare systems that lack a commitment to equity and a trauma-informed and historical framework" (Gonzales et al., 2018).

Moreover, the scholars indicate "Drawing on values that provide strength and empowerment to patients may help mitigate barriers to patient engagement, including communication processes between patients and providers" (Gonzales et al., 2018). Not to mention, the authors argue, "As such, cultural values are integral to what it means to be our best selves as Native American people, and these values are passed from one generation to the next to ensure healthy communities and thriving future generations" (Gonzales et al., 2018).

\section{Solutions}

After analyzing the values affirmation tool in Dr. Kelly's research and reading other health interventions. I would say both are great tools in the field of public health, one for helping the individual self-affirm before a visit to the clinic. Taber et al. (2016) discussed spontaneous self-affirmation on a micro-level was linked with eight out of 18 of the measures assessed; significant associations emerged for perceived quality of communication and care in medical setting... and being approached more often by others for medical advice" (p.7). Both data show 
a positive result of the tool, but there are confounding variables that must be tested before implementing this to future interventions. In essence, Spontaneous Self Affirmation (SSA), is crucial in a medical setting, to mitigate the health disparities that are present. However, my review is limited due to the minimal sources I used, and the field of public health with the minority population is very broad. Future research is needed in this area, of historical trauma, institutional racism, health disparities, mental health, and values affirmation tool. This paper has limitations due to one personal experience in the white academy; therefore, further studies are needed.

\section{My future- proud Latina leader}

My goal is to remove barriers that limit, prevent, inhibit the individuals from feeling less, lost, or lonely. I hope to promote a world that allows freedom and accepts the truth of every individual. I determined that I must prioritize my mental, emotional, and physical health to perform the best version of myself. With my identity, I can bring in diversity to the field of public health. My position in society (an Undergraduate student who is majoring in Health Studies: Community Health) aspiring to earn her Master's in the School of Public Health) allows me to find a place where I can put my acquired skills to practice simultaneously developing new ones on a hands-on practice or out in the real world. I hope I can encourage my people to break from their shell, practice self-affirmation, and comprehend that seeking help will not make you seem less. 
Lastly, expressing your true self is what matters every day. Living life to fullest, empowering one another, and spreading positivity will brighten future generations and the field of public health. The simple act of reflecting on one's strengths and values, holding true to oneself is a form of self-affirmation. I highly recommend every individual to remind themselves who they are, and to be open to any differences, in hope of a positive outcome. 


\section{Acknowledgments}

I would like to thank Kelly Gonzales for being part of my thesis preparation and completion. Her outstanding and unconditional support is impeccable. I have learned so much from her work, and I aspire to be someone like her. Additionally, I appreciate the Honors College and faculty for this amazing, laudable opportunity. Forever grateful. 


\section{References}

Benjamins, M, R., \& Middleton, M. (2019). Perceived discrimination in medical settings and perceived quality of care: A population-based study in Chicago. PloS one, 14(4).

Campbell, G. (2017).Overcoming Mental Health Stigma in the Latino Community Retrieved May 21, 2020, from https://consultqd.clevelandclinic.org/overcoming-mental-health-stigma-in-the-latino-com munity $/$

Camacho, A., Zangaro, G., \& White, K.M. (2017). Diversifying the health-care workforce begins at the pipeline: a 5-year synthesis of processes and outputs of the Scholarships for Disadvantaged Students program. Evaluation \& the health professions, 40(2), 127-150.

Carty, D. C., Kruger, D. J., Turner, T. M., Campbell, B., DeLoney, E. H., \& Lewis, E. Y. (2011). Racism, health status, and birth outcomes: Results of a participatory community-based intervention and health survey. Journal of Urban Health, 88(1), 84-97.

Cooper, L. A., \& Powe, N. R. (2004). Disparities in patient experiences, health care processes, and outcomes: the role of patient-provider racial, ethnic, and language concordance (pp. 7-1). New York, NY: Commonwealth Fund. 
Emanuel, A. S., Howell, J. L., Taber, J. M., Ferrer, R. A., Klein, W. M., \& Harris, P. R. (2018). Spontaneous self-affirmation is associated with psychological well-being: Evidence from a US national adult survey sample. Journal of health psychology, 23(1), 95-102.

Gonzales, K. L., Jacob, M. M., Mercier, A., Heater, H., Behind, L. N. G., Joseph, J., \& Kuerschner, S. (2018). An indigenous framework of the cycle of fetal alcohol spectrum disorder risk and prevention across the generations: historical trauma, harm and healing. Ethnicity \& Health, 1-19.

Healthy People 2020. (n.d.). Retrieved from https://www.healthypeople.gov/

Interian, A., Ang, A., Gara, M. A., Link, B. G., Rodriguez, M. A., \& Vega, W. A. (2010). Stigma and depression treatment utilization among Latinos: utility of four stigma measures. Psychiatric Services, 61(4), 373-379.

Joint Center for Political and Economic Studies. (2004). Community-based strategies for improving Latino health. Washington, D.C.

Mitchell, D. A., \& Lassiter, S. L. (2006). Addressing health care disparities and increasing workforce diversity: the next step for the dental, medical, and public health professions. American Journal of Public Health, 96(12), 2093-2097.

Parra-Cardona, J. R., López-Zerón, G., Domenech Rodríguez, M. M., Escobar-Chew, A. R., Whitehead, M. R., Sullivan, C. M., \& Bernal, G. (2016). A balancing act: Integrating 
evidence-based knowledge and cultural relevance in a program of prevention parenting research with Latino/immigrants. Family process, 55(2), 321-337.

Taber, J. M., Howell, J. L., Emanuel, A. S., Klein, W. M., Ferrer, R. A., \& Harris, P. R. (2016). Associations of spontaneous self-affirmation with health care experiences and health information seeking in a national survey of US adults. Psychology \& health, 31(3), 292-309.

Velasco-Mondragon, E., Jimenez, A., Palladino-Davis, A.G., Davis, D., \& Escamilla-Cejudo, J.A. (2016). Hispanic health in the USA: a scoping review of the literature. Public health reviews, 37,31 . 